\title{
Perceções de educadores cooperantes sobre o processo supervisivo
}

\section{Perceptions of cooperating educators on the supervisory process}

\author{
Angelina Sanches*, Rosa Novo**, Elza Mesquita* \\ *Departamento de Supervisão da Prática Pedagógica, Escola Superior de Educação do Instituto Politécnico de Bragança - Portugal. \\ **Departamento de Psicologia, Escola Superior de Educação do Instituto Politécnico de Bragança - Portugal.
}

\begin{abstract}
Resumo
O artigo apresenta um estudo que se sustenta em perspetivas de matriz socioconstrutivista e ecológica e procura aprofundar o conhecimento sobre as práticas de supervisão ao nível dos cursos que profissionalizam para a docência. Recorrendo a uma abordagem de natureza qualitativa e interpretativa aplicou-se um questionário com perguntas abertas, sendo inquiridos 73 cooperantes, dos quais 34 educadores de infância, grupo sobre o qual incide o texto. Os resultados são lidos atendendo a quatro dimensões: os papéis desempenhados pelos diferentes intervenientes do processo formativo (supervisor institucional, orientador cooperante, formando), as interações, o processo de reflexão e o de avaliação. Palavras-chave: supervisão, formação de educadores de infância, prática de ensino supervisionada
\end{abstract}

\begin{abstract}
The article presents a study that is based on perspectives of social constructivist and ecological matrix and seeks to deepen the knowledge of supervisory practices in the courses that professionalize for teaching. Using a qualitative and interpretative approach was applied a questionnaire with open questions, and respondents 73 aid workers, including 34 kindergarten teachers, group over which the text. The results are read attending the four dimensions: the roles played by different actors of the training process (institutional supervisor, cooperative advisor, forming), the interactions, the process of reflection and evaluation.
\end{abstract}

Keywords: supervision, training of kindergarten teachers, supervised teaching practice

\section{Introdução}

Considerando que a formação dos futuros educadores/professores deve pautar-se por critérios de qualidade e que as práticas supervisivas assumem relevância nesse processo, entendemos ser importante (re)equacionar como estas são percebidas pelos orientadores cooperantes. Nesta linha, e relevando o caráter de acompanhamento e monitorização que se atribui à supervisão (Alarcão \& Canha, 2013), importa compreender esse processo na relação com o saber profissional a construir pelos sujeitos em formação e a sua função social. Reportando-nos à formação de futuros educadores/professores, é de considerar que, como referem Alarcão e Roldão (2009), se trata de "alguém a

quem a sociedade confia a tarefa de criar contextos de desenvolvimento humano que envolvam o educando na multiplicidade e interactividade das suas dimensões: cognitiva, afectiva, psicomotora, linguística, relacional, comunicacional, ética” (p.16). É neste sentido que a supervisão se perspetiva, neste estudo, numa dimensão formativa, de matriz socioconstrutivista e ecológica, valorizando nesse processo a (inter)ação, a cooperação, a ética e a ação reflexiva emancipatória. Pressupõe-se o recurso a meios que facilitem o desenvolvimento desse processo, como os que se prendem com o observar, planear, agir, refletir, dialogar, comunicar e avaliar. Salienta-se a necessidade de orientar a supervisão numa linha de atuação integrada e de construção identitária do educador/professor, valorizando a colaboração e a partilha de saberes e experiências como elementos formativos fundamentais (Alarcão \& Sá-Chaves, 2011; Alarcão \& Roldão, 2009).

São ainda tidos em conta os contributos das orientações normativas previstas no atual quadro legislativo

(Decreto-Lei n. ${ }^{\circ} 43 / 2007$, de 22 de fevereiro; Decreto n. ${ }^{\circ}$ $79 / 2014$, de 14 de maio) em que a formação e a experiência em supervisão, bem como a prática docente são elementos valorizados no processo de supervisão.

Diversos autores têm apresentado preocupações quanto ao desenvolvimento de uma supervisão renovada. Tracy (2002) chama a atenção para o facto de a sala de atividades já não ser considerada o único espaço de supervisão. Embora, as formas tradicionais de ver a supervisão no quadro do triângulo supervisivo (formando, orientador cooperante supervisor institucional) sejam ainda válidas e úteis, apresentam-se claramente insuficientes, devendo haver a abertura deliberada aos contextos institucionais e à cultura envolvente (Oliveira-Formosinho, 2005; Harris, 2002; Tracy, 2002). Entende-se, então, a supervisão como uma ação mobilizadora e facilitadora de desenvolvimento do potencial de cada um e do coletivo dos intervenientes, bem como dos contextos envolvidos, não podendo deixar de considerar a influência que, entre si, podem exercer. Alarcão e Roldão (2009) baseando-se em resultados de um estudo desenvolvido na Universidade de Aveiro afirmam que os contextos presentes na formação e, sobretudo, o modo como se articulam afiguram-se como um dos principais fatores de desenvolvimento. Como caraterísticas favoráveis a contextos supervisivos de qualidade aponta-se que se apresentem dinâmicos, estimulantes e articulados. Outro aspeto reconhecido como fundamental na formação e desenvolvimento profissional é a capacidade de analisar e refletir, sublinhando o potencial formativo da reflexão quando 
esta é colaborativa. Todavia, como também afirmam Alarcão e Roldão (2009), os resultados do estudo dão conta de "práticas de reflexão incipientes, dificuldades em refletir e comunicar o teor das reflexões” (p. 30). As dificuldades em utilizar abordagens reflexivas são atribuídas aos diferentes intervenientes e o fator tempo surge referido como um constrangimento. Surgem também referências às dificuldades sentidas no âmbito da interpretação, do questionamento e do confronto de opiniões.

Também Azevedo (2012) aponta para que a supervisão se promova na base da reflexão e colaboração, entendendo que pode contribuir para a afirmação da autonomia dos professores, a construção de conhecimento profissional e a melhoria da qualidade da ação educativa. Todavia, de acordo com o estudo de Coimbra (2013), os professores apontam para a escassez de uma supervisão sólida, capaz de promover um ensino de qualidade e o desenvolvimento profissional. Evidencia, ainda, a necessidade de trabalho cooperativo entre as escolas e as instituições de ensino superior.

Acreditamos que as práticas supervisivas podem ser transformadas em ordem a uma progressiva melhoria, o que requer oportunidades de comunicação, abertura ao diálogo e à partilha de saberes, à ação colaborativa e investigativa. Perfilhamos a ideia de que o envolvimento na construção conjunta de conhecimento conduzirá a um maior comprometimento de todos com a melhoria das práticas formativas/supervisivas e educativas.

\section{Metodologia do estudo}

O presente estudo insere-se no âmbito de uma abordagem metodológica de natureza qualitativa e interpretativa. A problemática em estudo incide sobre a componente de iniciação à prática profissional e, em particular, sobre a supervisão pedagógica promovida ao nível da formação de educadores/professores na Escola Superior de Educação de Bragança (ESEB), Portugal.

Procura-se, assim, aprofundar o conhecimento sobre as práticas de supervisão em desenvolvimento na instituição em que nos integramos, ao nível da iniciação à prática profissional do curso de licenciatura em educação básica e da prática de ensino supervisionada dos cursos de mestrado que profissionalizam para a docência. A concretização deste objetivo baseou-se na constituição de uma amostra de conveniência, num total de 34 educadores de infância, que incluíram um grupo mais amplo de 73 orientadores cooperantes que participaram num estudo em desenvolvimento na ESEB. A técnica de amostragem utilizada para este estudo foi não probabilística acidental ou de conveniência, uma vez que, tal como refere Fortin (1999), trata-se de uma amostra constituída por indivíduos facilmente acessíveis e que respondem a critérios de inclusão precisos.

Assumindo um caráter descritivo e interpretativo dos dados, a pesquisa empírica recorre a um questionário com perguntas abertas que incidiram sobre o processo de supervisão, incluindo quatro categorias, nomeadamente: (a) papéis dos diferentes intervenientes; (b) interações; (c) organização da reflexão; e, (d) a avaliação, no processo supervisivo.

A recolha de dados, após obtenção do consentimento informado junto de cada educador cooperante, realizouse no final do ano letivo 2013-2014.

Os questionários foram sujeitos a uma análise de conteúdo, com um quadro de categorias previamente constituído, criando-se depois subcategorias a partir de indicadores de análise de sentido idêntico (Bardin, 2014).

O processo de categorização dos dados foi primeiro realizado por uma autora do estudo. Posteriormente discutiram-se com as outras autoras alguns exemplos desse processo a fim de melhorar a sua qualidade. Desta discussão resultaram pistas mais precisas para reconhecer e classificar os fragmentos de texto dentro das subcategorias definidas. Procurou-se assegurar a estabilidade da análise - vetor importante na determinação da fidelidade dos resultados - ou seja, a tendência para classificar e reclassificar o mesmo corpus de dados, da mesma forma. O desenvolvimento da estratégia analítica definida anteriormente colocou em evidência um fenómeno de saturação empírica (Glauser \& Strauss, citados por Guerra, 2006). Assim, para as quatro categorias previamente estabelecidas, foi possível ainda definir várias subcategorias que se apresentam na tabela 1 .

Tabela 1.

Sistema de categorias e subcategorias

\begin{tabular}{|c|c|}
\hline Categorias & Subcategorias \\
\hline \multirow{3}{*}{$\begin{array}{l}\text { Papéis dos diferentes } \\
\text { intervenientes }\end{array}$} & $\begin{array}{l}\text { Relevância de papéis } \\
\text { diferenciados }\end{array}$ \\
\hline & Valorização da colaboração \\
\hline & Constrangimentos \\
\hline \multirow[b]{2}{*}{ Interações } & $\begin{array}{l}\text { Valorização das relações } \\
\text { estabelecidas }\end{array}$ \\
\hline & $\begin{array}{l}\text { Necessidade de alargamento de } \\
\text { relações ao nível institucional }\end{array}$ \\
\hline \multirow{2}{*}{ Organização da reflexão } & $\begin{array}{l}\text { Pertinência da periodicidade no } \\
\text { seu desenvolvimento }\end{array}$ \\
\hline & Crítica ao processo \\
\hline \multirow{3}{*}{ Avaliação } & $\begin{array}{ll}\text { Processo regulador da } & \text { das formandos }\end{array}$ \\
\hline & $\begin{array}{l}\text { Processo facilitador da } \\
\text { (trans)formação dos contextos }\end{array}$ \\
\hline & Modos de operacionalização \\
\hline
\end{tabular}

\section{Descrição, análise e interpretação de dados}

Os dados obtidos foram cruzados com perspetivas teóricas, em particular com a conceptualização do modelo ecológico e socioconstrutivista de supervisão da formação de educadores de infância (OliveiraFormosinho, 2002; Alarcão \& Sá-Chaves, 
2011) e a investigação que coloca em evidência a formação em contexto, centrada na reconstrução da pedagogia da infância, no desenvolvimento profissional do educador e na qualidade dos contextos de educação de infância (Parente, 2004; Novo, 2009; Mesquita-Pires, 2013). Este cruzamento visou contribuir para o reforço da credibilidade das interpretações propostas e da validade do próprio estudo.

Ao longo do texto que se segue recorre-se à ordenação das categorias e subcategorias definidas e, para se ilustrarem, recorre-se a excertos do discurso das cooperantes para esclarecer a análise e a interpretação de dados (codificação atribuída através de um sistema alfanumérico de E1 a E34).

O conteúdo dos questionários centrado na categoria papéis dos diferentes intervenientes foi organizado em subcategorias como: (i) relevância de papéis diferenciados (ii) valorização da colaboração; (iii) e constrangimentos. A relevância de papéis diferenciados surge desdobrada num conjunto de papéis de cada um dos intervenientes. Os discursos permitem perceber que compete ao orientador cooperante (i) apoiar o formando na sua aprendizagem profissional, nomeadamente ajudando-o no conhecimento do grupo e dando orientação em relação aos temas a trabalhar; (ii) refletir sobre as atividades, projetos e planificações desenvolvidas; (iii) identificar os progressos que vai fazendo ao nível das competências, capacidades e atitudes associadas à profissão; e (iv) as dificuldades que deve ultrapassar até ao final do estágio. Relativamente ao papel do supervisor institucional sobressai: (i) mediar as relações entre os diversos intervenientes; (ii) apoiar o formando ao nível da reflexão e da planificação; (iii) orientar o formando na sua ação pedagógica; e (iv) apoiar o desenvolvimento profissional do formando. Em relação ao formando surgem relevados aspetos que se prendem com direitos e deveres, como: (i) usufruir de apoio na sua formação e intervenção; (ii) assumir responsabilidades no processo educativo; (iii) manifestar abertura, envolvimento e espírito crítico.

Ao nível da valorização da colaboração os educadores cooperantes, na sua maioria, relevam a importância do papel dos diferentes intervenientes (orientador cooperante, formando e supervisor institucional), mas acentuando uma supervisão colaborativa, como ilustram os seguintes exemplos: a instituição cooperou e coopera com tudo o que é necessário, houve sempre colaboração (E13); a instituição, uma vez que aceita estagiários, deve colaborar dentro das suas possibilidades, para que o estagiário se sinta membro necessário à instituição seja respeitado e valorizado o seu trabalho (E21). Parece então emergir claramente uma ação supervisiva "no sentido de uma orientação colaborativa e sistémica, onde aprender acerca do ensino seja responsabilidade de todos” sem, com isso, diluir a supervisão e ela não ser responsabilidade de ninguém (Garmston, Lipton \&

Kaiser, 2002, p.19).

Tal como é referido no estudo realizado por OliveiraFormosinho (2002), no âmbito da supervisão, existem fatores condicionadores relativamente à qualidade global da aprendizagem profissional que se pretende oferecer ao estagiário em formação, nomeadamente a falta de tempo para a supervisão pedagógica. No discurso das cooperantes também se enunciam constrangimentos como ilustram os seguintes excertos: o acompanhamento é muito escasso (E4); por vezes é complicado dar o apoio que os estagiários necessitam. Falta de tempo (E23); ao nível dos supervisores, poderiam ser mais presentes, no sentido de virem mais vezes aos centros de estágio, observar em 'contexto sala' (E8). É possível também identificar um aspeto recorrente, designadamente a maioria dos cooperantes reclama a necessidade de maior presença do supervisor institucional nos contextos educativos. Os excertos que se apresentam de seguida testemunham o papel impreterível do supervisor institucional para a construção de conhecimento acerca de competências profissionais, práticas que são indispensáveis na iniciação à profissão: penso que o supervisor de estágio deveria estar mais presente no estágio (E15); seria bom que o supervisor da ESEB tivesse mais disponibilidade de tempo para assistir às atividades orientadas pelos alunos no contexto educativo (E25).

No que se refere à categoria interações foram definidas as seguintes subcategorias: valorização das relações e necessidade de alargamento de relações ao nível institucional. Os cooperantes indicam perceber as relações promovidas entre os diferentes intervenientes de uma forma positiva, de respeito e proximidade, com grande grau de abertura, permitindo assim a partilha de preocupações e facilitando a resolução de problemas através da colaboração, bem como oportunidades de aprendizagem e conhecimento mútuo, como é possível constatar nos seguintes exemplos: as interações entre todos têm acontecido de forma salutar e aberta (E8); as interações são muito positivas (E15, E18). A relação entre os contextos formativos (escolas e ESEB) surge perspetivado numa linha de construção de uma ação cooperativa capaz de criar um ambiente de forma a facilitar a aprendizagem e desenvolvimento dos formandos. No que diz respeito à subcategoria necessidade de alargamento de relações ao nível institucional é visível nos discursos a necessidade de um diálogo mais alargado: existe comunicação entre supervisor e o professor cooperante, mas podia ser mais alargada (E29); era importante que houvesse mais diálogo entre os supervisores e educadores cooperantes (E3).

Quanto à organização da reflexão, a maioria dos inquiridos refere a adequação e pertinência da periodicidade semanal, mas aponta-se a necessidade de reflexões realizadas em grande grupo com o objetivo de trocar experiências, ampliar e aprofundar conhecimentos. Neste âmbito é de referir que na nossa instituição a reflexão sobre a prática é promovida em encontros semanais, quer a nível institucional (seminários e tutorias) quer a nível dos contextos cooperantes. Nos seminários de supervisão a partilha de experiências e de reflexões é alargada a toda a turma, sendo esta uma estratégia que favorece a continuidade no 
aprofundamento conceptual, através do feedback entre supervisores e alunos e dos alunos entre si. No entanto, observa-se ainda uma certa insatisfação pela forma como decorre a reflexão, como ilustram os seguintes excertos: as reflexões deveriam ser ativas, refletir mesmo no trabalho desenvolvido, notar os pontos fortes e fracos $e$ não limitarem-se ao 'correu bem', mas refletir para tentar melhorar (E31); as reuniões deveriam ser mais reflexivas por parte das alunas e não expositivas (E34); a escola deveria ter um papel mais interventivo nas reflexões (E10); a Escola Superior de Educação deveria organizar um guião de reflexão sobre o estágio (E19).

No que se refere à avaliação no processo supervisivo os dados relevam a vertente formativa que se pode assumir na aprendizagem e desenvolvimento profissional e pessoal dos formandos, atendendo a dimensões que favoreçam a construção de um saber profissional de natureza multidimensional. Neste âmbito os educadores cooperantes atendendo ao processo regulador da aprendizagem dos formandos salientam que a avaliação deve incidir nas dimensões científica, experiencial, investigativa e reflexiva indispensáveis, como os seguintes exemplos deixam perceber: é muito importante avaliar com rigor técnico e científico a prática de ensino supervisionada, confirmando se o futuro professor/educador adquiriu competências para se relacionar, interagir com as crianças e trabalhar com os pares (E2); na avaliação devemos ter em conta as relações interpessoais (...), o conhecimento científico/pedagógico e a ética profissional (E6); avaliar os conhecimentos científicos (...) as competências pessoais e profissionais (...), o empenho e a dedicação na elaboração das atividades e projetos adequados às crianças (E21).

Quanto ao processo de avaliação enquanto facilitador da (trans)formação dos contextos valoriza-se uma participação alargada a todos os implicados na supervisão: deverá contemplar a escola de formação, os alunos, os cooperantes $e$ as direções das escolas cooperantes (E19); devem intervir na avaliação todos os que de uma forma mais direta, são responsáveis pela supervisão e orientação dos estágios, com recurso a diversos instrumentos que levem os alunos evoluir de forma segura e confiante (E2);

Quanto à operacionalização da avaliação é acentuada a importância do acompanhamento e do feedback a proporcionar aos formandos no decurso da prática educativa, não reunindo consenso o modo como se apresenta, apontando alguns entendê-la como coerente com o desejado e outros que poderia ser melhorada, como as seguintes afirmações permitem entender: $\mathrm{em}$ meu entender a avaliação do processo de supervisão está a ser bem orientado, tanto nas dimensões a considerar como nos modos de operacionalização, bem como com os intervenientes (E14); a avaliação do processo de supervisão (...) tem que ser feita em todas as fases do processo (planificação, ação e reflexão). Nestas três vertentes penso que deveria haver mais reflexão (...) para melhorar o processo de formação de todos os intervenientes (E7); a instituição (...) deve reconhecer nos estagiários uma mais-valia para o desenvolvimento da prática pedagógica (E24).

$\mathrm{Na}$ lógica das ideias que fomos apontando percebemos que as situações formativas que envolvem pessoas em avaliação e outras que assumem a responsabilidade por essa mesma avaliação não podem, nem devem, ser simplificadas ou simplificadoras dos processos de decisão, devem ser antes complexas e complexificadoras desses mesmos processos, atendendo, obviamente a um trabalho de grupo assente numa cultura transformadora (Formosinho \& Machado, 2010).

\section{Considerações finais}

Os resultados do estudo podem ser lidos atendendo a quatro dimensões, nomeadamente os papéis desempenhados pelos diferentes intervenientes do processo formativo (supervisor institucional, orientador cooperante, formando), as interações, o processo de reflexão e o de avaliação. A leitura dos dados, e não obstante a ocorrência de algumas diferenças de opinião, releva a importância de enveredar por práticas supervisivas pautadas pela colaboração e partilha de conhecimentos, no quadro de uma vivência democrática e emancipatória. Relativamente às interações são percebidas como positivas, deixando antever um clima de bom entendimento e cooperação entre os diferentes atores. No que se refere ao processo de reflexão da práxis os resultados apontam para a necessidade de um maior investimento na construção de uma linguagem comum e potencialmente facilitadora do desenvolvimento pessoal e profissional de todos. A consciência de que a aprendizagem da profissão é uma jornada que exige reflexão crítica induz ao desenvolvimento de esforços, no sentido do aperfeiçoamento e consolidação dessa meta, um aspeto a merecer melhor atenção.

Sobre o processo de avaliação salienta-se o grau de exigência, uma autonomização gradual dos formandos, bem como algumas dificuldades, dado o tempo atribuído à prática de ensino supervisionada. O estudo remete para a importância de um contínuo investimento qualitativamente diferenciado à multiplicidade e diversidade dos contextos supervisivos. É percebida a

ideia de que os contextos e, em particular, o modo como se articulam afiguram-se como importantes fatores de desenvolvimento profissional e pessoal, apontando para uma perspetiva supervisiva de matriz socioconstrutivista e ecológica.

A qualidade da supervisão que se pratica é valorizada positivamente, não obstante a identificação de alguns constrangimentos e aspetos menos positivos a ultrapassar. Relevam-se práticas de supervisão acompanhadas, facilitadoras de uma autonomização progressiva dos sujeitos em formação e da sua implicação nesse processo. 


\section{Referências}

Alarcão. I, \& Canha, B. (2013). Supervisão e colaboração. Uma relação para o desenvolvimento. Porto: Porto Editora.

Alarcão, I. \& Roldão, M. C. (2009). Supervisão. Um contexto de desenvolvimento profissional dos professores. Mangualde: Edições Pedago.

Alarcão, I. \& Sá-Chaves, I. (2011). Supervisão de professores e desenvolvimento humano: uma perspetiva ecológica. In I. Sá-Chaves, Formação conhecimento $e$ supervisão: contributos nas áreas de formação de professores e de outros profissionais (pp.133-148). Aveiro: Universidade de Aveiro.

Azevedo, J. (2012). Nota de apresentação. Revista Portuguesa de Investigação Educacional, vol. 12, 3-5.

Bardin, L. (2014). Análise de conteúdo. Lisboa: Edições 70.

Coimbra, M. N. C. T. (2013). Supervision and evaluation: teachers' perspectives. Internacional Journal of Humanities and Social Science, vol. 3, n. ${ }^{\circ}$ 5, March, 6571.

Ferreira, P., \& Fernandes, F. (2013). Supervisão pedagógica em contexto de formação inicial de professores: conceitos e perspetivas. Atas do XII Congresso Internacional Galego-Português de Psicopedagogia (pp.2621-2633). Braga: Universidade do Minho

Formosinho, J. \& Machado, J. (2010). Os professores e a diferenciação docente - da especialização de funções à avaliação de desempenho. In J. Formosinho, J. Machado, \& J. Oliveira-Formosinho, Formação, desempenho $e$ avaliação de professores (pp.77-95). Mangualde: Edições Pedago.

Fortin, M. F. (1999). O processo de investigação: da concepção à realização. Camarate: Lusociência, Edições Técnicas e Científicas, Lda.

Garmston, R., Lipton, L., \& Kaiser, K. (2002). A psicologia da Supervisão. In Oliveira-Formosinho (org.). A supervisão na formação de professores II - da organização à pessoa (pp.17-132). Porto: Porto Editora.

Guerra, I. C. (1999). Pesquisa qualitativa e análise de conteúdo: Sentido e formas de uso. Rio de Janeiro: Lucema.

Harris, B. (2002). Paradigmas e parâmetros da supervisão em educação. In Oliveira-Formosinho (org.). A supervisão na formação de professores II - da organização à pessoa (pp.135-223). Porto: Porto Editora.

Mesquita-Pires, C. (2013). A voz da criança sobre a inovação pedagógica. Tese Doutoral, Instituto de Educação, Universidade do Minho, Braga, Portugal. http://repositorium.sdum.uminho.pt/bitstream/1822/25 441/1/A_Voz_da_Crianca.pdf.

Novo, R. (2009). A aprendizagem profissional da interacção adulto-criança: um estudo de caso multicontexto. Tese Doutoral, Instituto de Educação, Universidade do Minho, Braga, Portugal. http://repositorium.sdum.uminho.pt/handle/1822/10674.
Oliveira-Formosinho, J. (2005). Da formação dos supervisores cooperantes à formação dos futuros professores de crianças - o ciclo de homologia formativa. In C. Guimarães (org.), Perspectivas para educação infantil (pp. 3-31). São Paulo: Junqueira e Marin Editores.

Oliveira-Formosinho, J. (2002). Em direcção a um modelo ecológico de supervisão de professores. In J. OliveiraFormosinho (org.), A supervisão na formação de professores I - da sala à escola (pp.94-118). Porto: Porto Editora.

Parente, C. (2004). A construção de práticas alternativas de avaliação na pedagogia da infância: sete jornadas de aprendizagem. Tese Doutoral. Braga: Instituto de Estudos da Criança, Universidade do Minho.

Tracy, S. (2002). Modelos e abordagens. In OliveiraFormosinho (org.), A supervisão na formação de professores I - da sala à escola (pp.19-92). Porto: Porto Editora.

Vieira, F. (2009). Para uma visão transformadora da supervisão pedagógica. Edu. Soc. Campinas, vol. 29, n. ${ }^{\circ}$ 105, 197-217.

\section{Legislação}

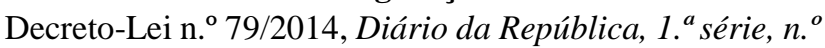
92, 14 de maio - Regime jurídico de habilitação profissional para a docência na educação pré-escolar e nos ensinos básico e secundário.

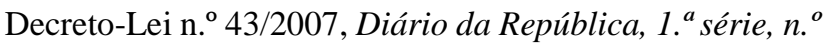
38, 22 de fevereiro - Regime jurídico de habilitação profissional para a docência na educação pré-escolar e nos ensinos básico e secundário. 